http://jmscr.igmpublication.org/home/ ISSN (e)-2347-176x ISSN (p) 2455-0450 crossref DOI: https://dx.doi.org/10.18535/jmscr/v8i3.106

\author{
Dournal Of Medical Science And Clinical Research \\ IGM Publication \\ An official Publication of IGM Publication
}

\title{
Correlation between Glycated Hemoglobin (HbA1c) Levels and Positive Tread Mill Test in Patients of Type 2 Diabetes Mellitus
}

\author{
Authors \\ Gopinath Subbaian ${ }^{1}$, Suresh.K ${ }^{1}$, Satish Babu' ${ }^{2}$ \\ ${ }^{1}$ Department of General Medicine, Sri Venkateshwaraa Medical College Hospital and Research Centre, \\ Pondicherry, India \\ ${ }^{2}$ Department of Cardiology, Sri Venkateshwaraa Medical College Hospital and Research Centre, \\ Pondicherry, India
}

\section{Introduction}

Type 2 diabetes mellitus (DM) has got a distinct association with coronary artery disease (CAD) . Diabetes mellitus is a metabolic disorder characterized by hyperglycemia resulting from defect in insulin secretion, insulin action or both. It may be accompanied by other biochemical disturbances and the presence of progressive diabetic tissue damage with micro and macrovascular complications.

\section{Aims and Objectives}

- To assess correlation between HbA1c levels in Type 2 diabetics and a positive Tread Mill Test

\section{Spectrum of Diabetes Mellitus}

Table 1: Spectrum of Diabetes Mellitus

\begin{tabular}{|l|c|c|c|}
\hline Types of Diabetes & $\begin{array}{c}\text { Normal Glucose } \\
\text { Tolerance }\end{array}$ & $\begin{array}{c}\text { Pre-diabetes/ impaired } \\
\text { fasting glucose/ } \\
\text { impaired glucose Tolerance }\end{array}$ & Diabetes Mellitus \\
\hline \multirow{2}{*}{ FPG } & $<5.6 \mathrm{mmol} / \mathrm{L}$ & $\begin{array}{c}5.6-6.9 \mathrm{mmol} / \mathrm{L} \\
(100-125 \mathrm{mg} / \mathrm{dL})\end{array}$ & $\geq 7 \mathrm{mmol} / \mathrm{L}$ \\
& $(100 \mathrm{mg} / \mathrm{dL})$ & $7.8-11 \mathrm{mmol} / \mathrm{L}$ & $\geq 11.1 \mathrm{mmol} / \mathrm{L}$ \\
2 2-h-PPG & $<7.8 \mathrm{mmol} / \mathrm{L}$ & $(140-199 \mathrm{mg} / \mathrm{dL})$ & $\geq 6.5 \%$ \\
\hline HbA1c & $(140 \mathrm{mg} / \mathrm{dL})$ & $5.7-6.4 \%$ & $\mathrm{mg} / \mathrm{dL})$ \\
\hline
\end{tabular}

\section{Glycated Hemoglobin: HbA1c}

Glycated hemoglobin (HbA1c) is derived from the non-enzymatic addition of glucose to amino groups of hemoglobin. HbA1c is a specific glycated hemoglobin that results from the attachment of glucose to the $\mathrm{N}$-terminal valine of the hemoglobin $\beta$-chain ${ }^{[66]}$.

\section{HbA1c As A Diagnostic Tool For Diabetes}

Glycation depends on the life span of RBC which is normally 120 days. ADA recommends the use of HbA1c as a diagnostic marker for diabetes and categories for increased risk of diabetes. Persons with HbA1c of $6.5 \%$ and above $(\geq 6.5 \%$ or 48 $\mathrm{mmol} / \mathrm{mol}$ ) are to be diagnosed as diabetes and 
HbA1c between 5.7-6.4 are considered to have pre-diabetes. The A1C test should be performed using a method that is certified by the NGSP (www.ngsp.org) and standardized or traceable to the Diabetes Control and Complications Trial (DCCT) reference assay.

\section{HbA1c Testing: ADA 2016 Recommendations}

- Perform the A1C test at least two times a year in patients who are meeting treatment goals (and who have stable glycemic control)

- Perform the A1C test quarterly in patients whose therapy has changed or who are not meeting glycemic goals.

\section{Treadmill}

\section{Bruce Protocol}

This is the most widely used protocol. It consists of 7 stages in which speed and grade are increased every 3 minutes. Bruce protocol has the advantage of being relatively short in duration. It also has many disadvantages. It's high workloads may not be suitable for most cardiac patients or elderly sedentary individuals. The large increments in work make the estimation of maximal oxygen consumption less accurate. The fourth stage can either be run or worked, which results in differing oxygen costs.

\section{Modified Bruce Protocol}

This protocol to an extent overcomes the disadvantages of the Bruce protocol. Here the first two stages are run at $1.7 \mathrm{mph}$ at $0 \%$ and $5 \%$ grades. The third stage of modified Bruce corresponds to 1 st stage of Bruce. The remaining stages correspond to that of Bruce protocol

\section{Method and Materials}

The present study was done to assess correlation between HbA1c levels in Type 2 diabetics and a positive Tread Mill Test.

It was carried out in Sri Venkateshwaraa medical college hospital and research centre which a 750 bedded multi disciplinary centre is serving the rural population. The study was carried out in the department of General Medicine in association with department of cardiology.

Type of Study: Cross-sectional study

Period of study: From July 2018 to June 2019 one year period

Study Population: Type 2 Diabetes Mellitus without established clinical diagnosis of coronary artery disease selected by random sampling from those admitted in medical wards and those who present to Medicine OPD.

Sample Size: 75 Patients.

\section{Inclusion Criteria}

$>$ Age above 40 years

$>$ Both gender (Male and Female)

$>$ All type 2 diabetic patients

$>$ Type 2 diabetic patients without any preexisting coronary artery disease.

$>$ Subjects with Normal resting ECG

$>$ Smoker and alcoholic patients

\section{Exclusion Criteria}

$>$ Established case of CAD

$>$ Age $<40$ years

$>$ Physically disable who cannot perform TMT

$>$ Osteoarthritis knee

$>$ Chronic kidney disease

$>$ Severe Anemia

$>$ ECG evidence of Q wave MI, Ischemic ST segment or $\mathrm{T}$ wave changes or Complete LBBB / RBBB

$>$ Severe Aortic stenosis, HOCM

$>$ Liver disease / malignancy

$>$ Peripheral Vascular disease

$>$ Patients with history of CVA

$>$ Patients on drugs affecting the heart

\section{Method of Data Collection}

All type 2 diabetic patients attending to medical and cardiology department in Sri Venkateshwaraa medical college hospital and research centre were included in the study after obtaining informed consent and description of the procedure. After documenting the demographic data of the patients a details clinical history and details of diabetes was obtained from the patients. A thorough general physical examination and a detailed 
systemic examination was obtained and documented as in Proforma.

\section{Interventions/Investigations Needed \\ ECG}

HbA1c

Treadmill test

\section{Statistical Analysis}

Patient's demographic data and results will be analyzed using descriptive statistics like mean and standard deviation. The data during the study will be collected and tabulated in Microsoft Excel. The data thus obtained will be analyzed by statistical package for social service (SPSS) version 23.

\section{Results}

Table 3: Gender Distribution of Study Population

\begin{tabular}{|c|c|c|}
\hline GENDER & No. of Patients & $\%$ \\
\hline MALE & $\mathbf{4 5}$ & $\mathbf{6 0}$ \\
\hline FEMALE & $\mathbf{3 0}$ & $\mathbf{4 0}$ \\
\hline TOTAL & $\mathbf{7 5}$ & $\mathbf{1 0 0 \%}$ \\
\hline
\end{tabular}

Table 7: HbA1c Distribution of the Study Population

\begin{tabular}{|l|c|}
\hline HbA1c LEVEL & No. of subjects \\
\hline$<7 \%$ & 36 \\
\hline $7.1-8 \%$ & 13 \\
\hline $8.1-10 \%$ & 19 \\
\hline$>10 \%$ & 07 \\
\hline Total & 75 \\
\hline
\end{tabular}

Table 10: TMT Pattern among Subjects

\begin{tabular}{|c|c|c|c|}
\hline $\begin{array}{c}\text { TMT } \\
\text { results }\end{array}$ & Male & Female & Total \\
\hline Positive & $08(17.78 \%)$ & $06(20 \%)$ & $14(18.67 \%)$ \\
\hline Negative & $37(82.22 \%)$ & $24(80 \%)$ & $61(81.33 \%)$ \\
\hline Total & $45(100 \%)$ & $30(100 \%)$ & $75(100 \%)$ \\
\hline
\end{tabular}

Table 13: TMT in Relation with HbA1c

\begin{tabular}{|l|c|c|c|}
\hline \multirow{2}{*}{ HbA1c } & \multicolumn{2}{|c|}{ TMT RESULTS } & \multirow{2}{*}{ p VALUE } \\
\cline { 2 - 4 } & Positive & Negative & \\
\hline$<\mathbf{7 \%}$ & 01 & 35 & $\mathrm{p}=0.015$ \\
\hline $\mathbf{7 . 1 - 8 \%}$ & 02 & 11 & $\mathrm{p}=0.495$ \\
\hline $\mathbf{8 . 1 - 1 0 \%}$ & 07 & 12 & $\mathrm{p}=0.589$ \\
\hline$>\mathbf{1 0 \%}$ & 04 & 03 & $\mathrm{p}=0.295$ \\
\hline
\end{tabular}

\section{Discussion}

Our observation in the study as follows:

In the present study of 75 cases $45(60 \%)$ were males and 30(40\%) were females.

In the present study HbA1c level were found $\leq 7 \%$
(36 Patients), 7.1-8.0 (13 Patients), 8.1-10 (19 Patients) and $\geq 10 \quad$ (7 Patients) respectively (Fig.Table-5).

In the present study, we found 50\% (7 Patients) with HbA1c 8.1-10\%, 28.6\% (4 Patients) with HbA1c >10\%, 14.3\% (2 Patients) with HbA1c $7.1-8 \%$ and $7 \%$ (1 Patient) with HbA1c $<7 \%$ had positive TMT. (Table-11) Swaminathan et al ${ }^{[21]}$ had shown statistically significant positive TMT in asymptomatic T2DM patients with $\mathrm{HbA1C}$ more than $9.7 \%$.

\section{Conclusion}

In the present study done to assess correlation between HbA1c levels in Type 2 diabetics and positive Tread Mill Test.

was done in Sri Venkateshwaraa medical college and hospital. Our study outcomes were

$>$ In our study we observed that $18.67 \%$ of patients had a positive TMT.

$>$ Glycosylated hemoglobin levels were found to be more in Diabetics, who had greater prevalence of inducible ischemia in asymptomatic type $2 \mathrm{DM}$.

\section{Summary}

- In my study out of 75 cases 45 were males and 30 were females.

- In the study population, more number of patients (26 i.e., 52\%) were having diabetes with duration of 6-10 years were more and was not statistically significant with inducible ischemia.

Out of 75 DM cases in my study, Treadmill test positive cases were $15(18.67 \%)$ and negative cases were $60(>80 \%)$ patients .

In the present study we found $\mathrm{HbA1C}(\%)$ is directly proportional to positive Treadmill test.

In summary, type $2 \mathrm{DM}$ had a increased risk of coronary artery disease if they were longer duration of DM, and elevated HbA1C levels even though they are asymptomatic. Based on our study, a routine screening test to detect inducible ischemia in asymptomatic type $2 \mathrm{DM}$ patients. 


\section{References}

1. Lavekar AS, Salkar HR (2013) Treadmill Test to Detect Stress Induced Ischemic Heart Disease in Type 2 Diabetes Mellitus Patients Asymptomatic for CAD: A Hospital Based Cross-sectional Study in Rural Population of Central India. J Diabetes Metab 4:244. doi: 10.4172/2155-6156.1000244.

2. Kannel WB. HC Gee-Diabetes and glucose tolerance as risk factors of cardiovascular disease, the Framingham study. Diabetes care 1997: 2: 120-31.

3. Raheja BS. Heart disease in diabetes. Aetiopathogenesis in $\mathbf{J}$ of Assoc of Phy of Ind 1980; 28: 81-90.

4. Joshi AS, Lahane CG, Kashid AA. The result of treadmill test in asymptomatic type 2 diabetes mellitus. Int J Sci Rep 2017; 3(6):166-72.

5. Singh AP, Singhal A. Study toDetermine the Diagnostic Utility of Treadmill Test in Asymptomatic Coronary Artery Disease Patients with Type2 Diabetes Mellitus. Ann. Int. Med. Den. Res. 2018; 4(4):ME21-ME24.

6. K.Swaminathan, M. Gayathri. Study of Treadmill test in Detecting Asymptomatic Coronary Artery Disease in Type 2 Diabetes Mellitus. 2016;15:01-06.

7. Meenaxi Sharda, Anil Kumar Soni, Shivraj Meena, Harish Nigam, Anuraj Singh. A Prospective Study on Utility of Exercise Treadmill Test in Type 2 Diabetes Mellitus Patients. Journal of The Association of Physicians of India. 2016; 64:32-37.

8. Ajay Kumar, V K Sing. Screening for Silent Myocardial Ischemia by Application of Exercise Stress Test: An Observational Cross-Sectional Study. International Journal of Scientific Study. 2014; 2:91-95.

9. Rajesh Kumar Gupta, Rimzim Gupta, Shashank Chaudhary, Himanshu Bhatheja, Prashant Pathak. Assessment of
Asymptomatic Coronary Heart Disease in Type 2 Diabetics with Treadmill Test and Framingham 10-Year CHD Risk Scoring System. Journal of Cardiovascular Disease Research. 2015; 6:131-37.

10. Narayan Chandra Sarkar, Siddhant Jain, Piyabi Sarkar, Mahendra Tilkar, Nitin Modi. Early detection of coronary artery disease in asymptomatic type 2 diabetes mellitus patients. IJAM. 2015; 2:26-29.

11. American Diabetes Association. Diagnosis and Classification of Diabetes Mellitus. Diabetes Care 2014;37 (Suppl. 1):S81S90

12. A Ramachandran, C Snehalatha. Diabetes Mellitus: Epidemiology and basic considerations of diabetes. YP Munjal, SK Sharma, editors. API Textbook of Medicine. $10^{\text {th }}$ ed. Vol.1. Mumbai: YP Munjal;2015:Part 9. Chap.1.p47-460.

13. Barman S, Barrett K, Boitano S, Brooks H, Ganong W. Endocine Functions of the Pancreas and Regulation of Carbohydrate Metabolism. Ganong's review of medical physiology[e-book].24 ${ }^{\text {th }}$ ed. McGraw-Hill Companies;2012: p431-451

14. Muralidhar S Rao. Diabetes Mellitus: Macrovascular Complications of Diabetes. YP Munjal, SK Sharma, editors. API Textbook of Medicine. $10^{\text {th }}$ ed. Vol.1. Mumbai: YP Munjal;2015: Part 9. Chap.13.p519-523.

15. International Expert Committee report on the role of the A1C assay in the diagnosis of diabetes. Diabetes Care 2009; 32:13271334.

16. Gallagher EJ, Bloomgarden ZT, Le Roith D. Review of hemoglobinA1C in the management of diabetes. Journal of Diabetes 2009; 1:9-17

17. Koeing RJ et al. Correlation of glucose regulation and hemoglobin A1c in diabetes mellitus. N Engl J Med 1976;295(8):41720

18. Makris K, Spanou L. Is there relationship between mean blood glucose and glycated 
hemoglobin. J Diabetes Sci Technol 2011;5(6):1572-583

19. Gonen B, Rubenstein AH, Rochman H, Tanega SP, Horwitz DL. Haemoglobin A1c: An indicator of the metabolic control of diabetic patients: The Lancet 1977;73437

20. Koeing RJ, Peterson CM, Kilocharles, Cerami Anthony, Williamson JR. Hemoglobin A1c as an indicator of degree of glucose intolerance in diabetes. Diabetes

21. Sanon S, Patel R, Eshelbrenner C, Sanon V, Alhaddad M, Oliveros R et al. Acute Coronary Syndrome in Patients with Diabetes Mellitus: Perspectives of an Interventional Cardiologist. The American Journal of Cardiology. 2012;110 (9):13B23B. 